\title{
Preparation of biochar via pyrolysis at laboratory and pilot scales to remove antibiotics and immobilize heavy metals in livestock feces
}

Tian, Renqiang; Li, Chunxing; Xie, Shengyu; You, Futian; Cao, Zhihong; Xu, Zhihong; Yu, Guangwei; Wang, Yin

Published in:

Journal of Soils and Sediments

Link to article, DOI:

$10.1007 / \mathrm{s} 11368-019-02350-2$

Publication date:

2019

Document Version

Peer reviewed version

Link back to DTU Orbit

Citation (APA):

Tian, R., Li, C., Xie, S., You, F., Cao, Z., Xu, Z., Yu, G., \& Wang, Y. (2019). Preparation of biochar via pyrolysis at laboratory and pilot scales to remove antibiotics and immobilize heavy metals in livestock feces. Journal of Soils and Sediments, 19(7), 2891-2902. https://doi.org/10.1007/s11368-019-02350-2

\section{General rights}

Copyright and moral rights for the publications made accessible in the public portal are retained by the authors and/or other copyright owners and it is a condition of accessing publications that users recognise and abide by the legal requirements associated with these rights.

- Users may download and print one copy of any publication from the public portal for the purpose of private study or research.

- You may not further distribute the material or use it for any profit-making activity or commercial gain

- You may freely distribute the URL identifying the publication in the public portal 
1 On preparation of biochar via pyrolysis at laboratory and pilot-

2 scales for removing antibiotics and immobilizing heavy metals in

Renqiang Tian ${ }^{1,3 \#}$, Chunxing Li ${ }^{1,2 \#}$, Shengyu Xie ${ }^{1,3}$, Futian You ${ }^{1}$, Zhihong $\mathrm{Cao}^{4}$,

$6{ }^{1}$ Key Laboratory of Urban Pollutant Conversion, Institute of Urban Environment,

7 Chinese Academy of Sciences, Xiamen 361021, China

$8 \quad{ }^{2}$ Department of Environmental Engineering, Technical University of Denmark, DK-

92800 Lyngby, Denmark

$10 \quad{ }^{3}$ University of Chinese Academy of Sciences, Beijing 100049, China

$11{ }^{4}$ State Key Laboratory of Soil and Sustainable Agriculture, Institute of Soil Science,

12 Chinese Academy of Sciences, Nanjing 210008, China

$13{ }^{5}$ Environmental Futures Research Institute and School of Environment and Science,

14 Griffith University, Brisbane, Queensland 4111, Australia

15 *Corresponding author. E-mail: yinwang@iue.ac.cn

$16{ }^{\#}$ The first two authors contribute to the work equally 


\section{Abstract}

Purpose Pyrolysis is the most effective way to completely remove antibiotics and immobilize heavy metals from livestock feces. However, the effect of pyrolysis temperature on antibiotics removal at laboratory and pilot-scales is still unclear.

Materials and methods The pyrolysis technique was used to convert pig manure $(\mathrm{PM})$ and chicken manure $(\mathrm{CM})$ into biochar at different temperatures from 300 to $700{ }^{\circ} \mathrm{C}$ in the laboratory-scale test. The performances of antibiotics removal and heavy metals immobilization in livestock feces were studied. Therefore, the optimal temperature of $600{ }^{\circ} \mathrm{C}$ was selected for pilot-scale verification.

Results and discussion The results showed the removal of antibiotics of Tylosin (TYL), Tetracycline (TC), Chlortetracycline (CTC), Doxycycline (DOXY), Sulfamethazine (SMZ), Sulfadiazine (SDZ) and Sulfamethoxazole (SMX) was satisfactory, with all of the seven typical antibiotics totally removed at $600{ }^{\circ} \mathrm{C}$. The heavy metals of zinc $(\mathrm{Zn})$, copper $(\mathrm{Cu})$, chromium $(\mathrm{Cr})$, lead $(\mathrm{Pb})$, nickel $(\mathrm{Ni})$, cadmium (Cd) and arsenic (As) in the manures were well immobilized as well, while higher temperatures (above $600{ }^{\circ} \mathrm{C}$ ) favored their immobilization. The results in heavy metals immobilization and antibiotics removal of pilot-scale test were similar to that of the laboratory test.

Conclusions Laboratory and pilot-scale studies showed that the current study provides a safe method and technology for treating and recycling livestock feces into biochar via pyrolysis process.

Keywords Livestock feces; Pyrolysis; Biochar; Antibiotics removal; Heavy metals immobilization; Pilot-scale. 


\section{Introduction}

With the development of economy and increase in living standard, more and more livestock products are consumed, which leads to the results of large amounts of livestock feces. It was reported that about 250 million tons of livestock feces were produced annually in China (Yang et al. 2017). These manures will cause serious environmental problems if without proper treatments. For example, the manure contains high content of nitrogen and phosphorus, which can pollute the air and underground water if discharged directly. In the past, the manure was directly used as organic fertilizer to enhance the growth of crops (Feng et al. 2018). However, the new environmental issues concerned on manures occurred during applying and treating livestock feces. With the huge demand of livestock products, many additives with excess trace elements (especially $\mathrm{Cu}$ and $\mathrm{Zn}$ ) and antibiotics were added in feeds to avoid diseases and enhance growth (Qiao et al. 2012; Wang et al. 2013). Most of the heavy metals and antibiotics added in feeds cannot be totally absorbed by livestock and then excreted via manures (Zeng et al. 2018; Zhou et al. 2019), which increased obviously the potential environment risks. Both the heavy metals and antibiotics pose a threat to environment and human health seriously.

Currently, valuable products generation and energy recovery from livestock feces with simultaneous safe treatment attract much attention and interests. In terms of different livestock feces treatment approaches, pyrolysis presents obvious advantages and has been well used for the dispose of sewage sludge and other kinds of solid wastes with additional targets of biochar generation, nutrient recycling and heavy metals immobilization (Yargicoglu et al. 2015; Troy et al. 2013; Wang et al. 2016). The obtained biochar that has many special characteristics can also be further utilized. For example, it was used to remove pollutants in water and soil as effective sorbent, 
improve fertility and grain yield as soil amendment and enhance sewage sludge dewaterability as skeleton structure. (Ehsan et al. 2014; Tan et al. 2017; Li et al. 2018b).(Khorram et al. 2016; Zhang et al. 2016). (Xie et al. 2019). Some other researches were conducted to investigate the effect of pyrolysis on heavy metals immobilization during manures treatment. Lin et al. (2017) studied the impact of various pyrolysis temperatures on the speciation, leachability and bio-accessibility of $\mathrm{Cu}$ and $\mathrm{Zn}$ in animal manure-derived biochar. Zeng et al. (2018) reported the performance of different heavy metals during swine and goat manures pyrolysis, and found that the heavy metals were well immobilized after pyrolysis and higher temperature favored better performance. Other researchers found that the biochar could immobilize and adsorb the heavy metals in soil (Uchimiya and Bannon 2013; Ehsan et al. 2014), supplying useful approach for biochar application. In terms of another tough problem of antibiotics in livestock feces, the composting treatment can effectively reduce the antibiotics and part of antibiotics resistance genes. While, it is difficult to remove the antibiotics thoroughly, because some kinds of antibiotics cannot be degraded completely during compost due to their steady molecular structure (Pruden et al. 2013). Another question is if composting and fermentation eliminate some antibiotic and resistance genes, and then must resulting another stronger microbes and resistance genes (Zhou et al. 2019a). How can these new stronger microbes and resistance genes be eliminated to ensure human safety? Our previous study proved that converting pig manure into biochar could successfully decline the antibiotic resistance genes (Zhou et al. 2019b), which indicated that the antibiotics could be completely decomposed under rigorous pyrolysis conditions, and further obviously reduced the environmental pollution caused by antibiotics.

However, there were little researches on the effect of pyrolysis temperature on 
the removal of antibiotics in livestock feces pyrolysis. In addition, although heavy metals immobilization during pyrolysis process was studied by some researchers, there was little information on pilot-scale verification under optimized pyrolysis condition to supply operational information for the industrialization. Therefore, the following contents were deeply studied in this work: (1) Effect of pyrolysis temperature on the removal of antibiotics in PM and CM. (2) Immobilization performance of heavy metals in the biochar samples obtained from PM and CM. (3) Pilot-scale verification under optimal pyrolysis condition. In general, this work gives comprehensive investigation in simultaneous antibiotic removal and heavy metals immobilization during PM and CM pyrolysis from laboratory-scale research to pilotscale verification.

\section{Materials and Methods}

\subsection{Materials and biochar characterization}

The used PM and CM were obtained from a livestock and poultry farm in Xiamen and Zhangzhou, respectively, Fujian province, China. The PM and CM were smashed to 100 mesh $(0.15 \mathrm{~mm})$ after freeze dried at $-55{ }^{\circ} \mathrm{C}$ for $24 \mathrm{~h}$ to remove moisture, then stored at a dryer for further analysis and tests.

The ultimate analysis of the PM, CM and their biochar samples were measured using an elemental analyzer (VARIO MAX, Germany), and the proximate analysis was tested according to the Chinese standard methods (GB/T 28731-2012). A pH meter (Denver, UB-7, USA) was operated to get the $\mathrm{pH}$ of raw and biochar samples. The textural parameters of the raw and biochar samples were measured via BET-N 2 (ASAP-2020, USA), and the FT-IR spectrometry (iS10, Thermo, USA) was applied to analyze the surface functional groups of the raw and biochar samples. The thermal properties of different antibiotics were measured in a thermogravimetric analyzer (TG 
209 F3, Netzsch, Germany), and the detail supplemental information of the seven different antibiotics was listed in Table S1. All the heavy metals contents were tested by the inductively coupled plasma mass spectrometry (ICP-MS Agilent 7500cx, USA). The concentrations of different antibiotics were measured by the ultra performance liquid chromatography-tandem triple quadrupole mass spectrometer (ABI 6500, Applied Biology Company, America).

\subsection{Analysis of the heavy metals}

Fraction procedure of heavy metals: A three-step BCR extraction procedure was applied to extract the heavy metals in the PM, CM and their biochar samples. And the heavy metals were divided into four fractions including F1: acid soluble/exchangeable fraction; F2: reducible fraction; F3: oxidizable fraction and F4: residual fraction, which was described by European Community Bureau of Reference (BCR). The detailed information of BCR extraction procedure can be found in our previous work (Wang et al. 2019a). To obtain the F1-F3, the suspension was centrifuged at centrifugation factor of $3820.2(\times \mathrm{g})$ for $20 \mathrm{~min}$ and then filtered through a $0.22 \mu \mathrm{m}$ filter. The filtrate was then diluted using $\mathrm{HNO}_{3}(2 \%)$ to a constant volume of $50 \mathrm{~mL}$. The obtained filtrate was digested using the mixed acid of $\mathrm{H}_{2} \mathrm{O}_{2} / \mathrm{HNO}_{3}$ to remove the dissolved organics. The $\mathrm{F} 4$ and total content of heavy metals in the PM, CM and biochar samples were determined after digestion using a microwave digestion system with an acid mixture $\left(\mathrm{HNO}_{3}: \mathrm{HClO}_{4}: \mathrm{HF}=5: 5: 2\right.$, $\mathrm{v} / \mathrm{v} / \mathrm{v}$ ), and then filtrated via the $0.22 \mu \mathrm{m}$ nylon filter before measurement. Each test was operated three times to keep the data accuracy and the values were presented as mean values \pm standard deviation.

Leaching experiments: The availability and toxicity heavy metals in PM, CM and the biochar samples were impacted by their leachability assessed by the toxicity 
characteristic leaching procedure (TCLP) (Xie et al. 2019). For the TCLP, the glacial acetic acid solution with $\mathrm{pH}$ of 2.88 was used for extraction with liquid/solid ratio of 20:1. After extraction in the polyethylene tubes and shaken at $200 \mathrm{rpm}$ for 18 hours in a shaking incubator, the supernatant was obtained via centrifugation for digestion with $\mathrm{H}_{2} \mathrm{O}_{2} / \mathrm{HNO}_{3}$, and then filtrated through $0.22 \mu \mathrm{m}$ membrane filters for measurement of heavy metals.

Evaluation of risk assessment code: The widely used evaluation of risk assessment code (RAC) was employed to assess the heavy metal toxicity (Leng et al. 2016). The percentage of F1 was used to represent the RAC, which included five degrees: no risk (NR), lower than 1\%; low risk (LR), 1-10\%; medium risk (MR), 1130\%; high risk (HR), 31-50\%; very high risk (VHR), higher than 50\% (Zhai et al. 2014).

\subsection{Extraction and measurement of the antibiotics}

The dried and homogenized samples $(0.5 \mathrm{~g}$ of raw PM, CM or $1 \mathrm{~g}$ of their biochar samples) were added into polytetrafluoroethylene centrifuge tube (50 ml), and $1 \mathrm{~mL}$ of the standard solution of $100 \mu \mathrm{g} / \mathrm{L}$ was also spiked. Then the samples were mixed and placed in a refrigerator at $4{ }^{\circ} \mathrm{C}$ overnight. After adding $15 \mathrm{~mL}$ of extraction solvent (EDTA-McIIvaine buffer: methanol: acetonitrile $=5: 3: 2, \mathrm{v} / \mathrm{v} / \mathrm{v}$ ) and mixing on a vortex mixer at $25 \pm 1{ }^{\circ} \mathrm{C}$ in the dark for $1 \mathrm{~min}$, all the tubes were ultrasonicated for $15 \mathrm{~min}$ and then centrifuged at centrifugation factor of 5000 for $10 \mathrm{~min}$. The obtained supernatant and residue were decanted into a brown glass bottle and extracted with extraction solvent $(10 \mathrm{~mL})$ once more, respectively, and the procedure was repeated twice. When the combined supernatants from the three extractions were filtered through a $0.45 \mu \mathrm{m}$ glass microfiber (GF/F, Whatman), they were diluted to $500 \mathrm{~mL}$ using ultrapure water to keep the organic solvent content $\leq 5 \%$ in the 
solution. More detailed information about the solid phase extraction and purification can be obtained in the literature (Huang et al. 2013). The final obtained samples were stored at $4{ }^{\circ} \mathrm{C}$ before measurement. The detailed information of the applied method for all the antibiotics was listed in Table S2. The recoveries for PM, CM and their biochar samples were relevant high, which proved the feasibility of the applied extraction method.

\subsection{Laboratory and pilot-scales pyrolysis experiments}

All the laboratory-scale pyrolysis experiments were conducted in a fixed bed quartz reactor (Fig. S1a). The pyrolysis temperature varied from 300 to $700{ }^{\circ} \mathrm{C}$. For each experiment, $40 \mathrm{~g}$ of $\mathrm{PM}$ or $\mathrm{CM}$ was inserted into the quartz reactor, and then $\mathrm{N}_{2}$ $(80 \mathrm{~mL} / \mathrm{min})$ was introduced for removing the air in the reactor to create an oxygenfree environment. After that, it was prepared as follows: heating the reactor to preset temperatures with heating rate of $15{ }^{\circ} \mathrm{C} / \mathrm{min}$; keeping for $45 \mathrm{~min}$; cooling the reactor to room temperature; taking out the biochar from quartz reactor. At last, the obtained biochar was kept in a dryer for further characterization analysis.

For the pilot-scale pyrolysis experiments, it was done in a rotary furnace with 6.0 $\mathrm{m}$ in length, $1.5 \mathrm{~m}$ in width and $1.5 \mathrm{~m}$ in height, and the schematic diagram can be found in Fig. S1b. A screw feeder was applied to feed the PM or CM into the rotary furnace with a treatment capacity of 6 t per day. The rotary furnace was heated by burning wood pellets to keep the temperature at $600 \pm 50^{\circ} \mathrm{C}$, and the produced biogas/oil was recycled into the chamber and burnt to supply the energy consumed during pyrolysis process. There were three ventilators and thermocouples to supply oxygen for combustion and measure the temperatures, respectively. The retention time for PM or CM in the furnace was about $45 \mathrm{~min}$. The generated biochar was cooled in an oxygen-free environment, and the detailed information about the pilot-scale 
pyrolysis process can be found in our previous study (Li et al. 2018a).

\section{Results and Discussion}

\subsection{Effect of pyrolysis temperature on the biochar}

\subsubsection{Characterization of biochar made from PM and CM}

To characterize biochar made from $\mathrm{PM}$ and $\mathrm{CM}$ at different pyrolysis temperatures, the proximate and ultimate analysis, biochar yield, $\mathrm{pH}$ value and specific surface area $\left(\mathrm{S}_{\mathrm{BET}}\right)$ were measured and the results were summarized in Table 1. The biochar yields decreased with the pyrolysis temperature from 300 to $700{ }^{\circ} \mathrm{C}$ (50.91 to $35.93 \%$ for $\mathrm{PM}$ and 52.82 to $36.07 \%$ for $\mathrm{CM}$ ), which resulted from the decomposition of organic matters (Jin et al. 2016). The ash content obviously increased due to the concentrated minerals and loss of organic matters. And the $\mathrm{pH}$ presented the opposite trend with the change of biochar yield. It was explained that the alkali salt was released and the acidic surface functional groups decreased during pyrolysis process, causing $\mathrm{pH}$ raising from 8.10 to 13.08 for CM (Zheng et al. 2013). In addition, the high $\mathrm{pH}$ of biochar samples indicated that it could be used as acid soil amendment. Compared with the $\mathrm{S}_{\mathrm{BET}}$ of raw PM and CM, improving pyrolysis temperature obviously enhanced the $\mathrm{S}_{\mathrm{BET}}$ values, such as from 0.08 to $20.91 \mathrm{~m}^{2} / \mathrm{g}$ for PM, which was resulted from the aggravation of carbonization degree (Jin et al. 2016). In terms of ultimate analysis, all the element contents (except C) decreased with rising pyrolysis temperature due to the continuous decomposition of volatile matters. And the increase trend of $\mathrm{C}$ with the pyrolysis temperature was due to the high content of fixed carbon in the raw materials concentrated with decomposition of organic matters during pyrolysis process.

\subsubsection{FTIR spectra analysis of PM, CM and their biochars}

To further identify the change of chemical functional groups under various 
pyrolysis temperatures, the FTIR spectra was used to analyze the PM, CM and their biochars. Fig. 1 indicates that before pyrolysis, PM and CM showed similar FT-IR spectra with major peaks at 3405-3443 $\mathrm{cm}^{-1}, 2923$ and $2834 \mathrm{~cm}^{-1}, 1647 \mathrm{~cm}^{-1}, 1584$ $\mathrm{cm}^{-1}, 1400-1440 \mathrm{~cm}^{-1}, 1230 \mathrm{~cm}^{-1}$, and $1060 \mathrm{~cm}^{-1}$, which correspond to $\mathrm{v}(-\mathrm{OH}), v_{\mathrm{as}}(-$ $\left.\mathrm{CH}_{2}\right)$ and $v_{\mathrm{s}}\left(-\mathrm{CH}_{2}\right), v(-\mathrm{C}(\mathrm{O}) \mathrm{NH}-), v(\mathrm{C}=\mathrm{C}), \delta(-\mathrm{OH})$ and $\delta(\mathrm{CH}), \rho\left(-\mathrm{CH}_{2}\right)$, and $v(\mathrm{C}-\mathrm{OH})$, respectively (Agrafioti et al. 2013; Li et al. 2018b; Yang et al. 2007; You et al. 2019). When PM and CM were pyrolyzed at $300{ }^{\circ} \mathrm{C}$, all peaks were largely reduced in their intensities, especially $v(-\mathrm{OH}), v_{\text {as }}\left(-\mathrm{CH}_{2}\right), v_{\mathrm{s}}\left(-\mathrm{CH}_{2}\right), v(-\mathrm{C}(\mathrm{O}) \mathrm{NH}-), \delta(-\mathrm{OH})$ and $\rho\left(-\mathrm{CH}_{2}\right)$. Therefore, the phenol, methylene and amides groups were almost eliminated so that the cellulose structures of PM and CM were transformed into carbonaceous structures of biochar. In the spectra of PM300 and CM300, typical peaks of biochar can be identified at $1584 \mathrm{~cm}^{-1}, 1402 \mathrm{~cm}^{-1}$ and $1060 \mathrm{~cm}^{-1}$, which correspond to $v(\mathrm{C}=\mathrm{C}), \delta(\mathrm{CH})$ and $v(\mathrm{C}-\mathrm{O})$, respectively (You et al. 2019). As the pyrolysis temperature increased to over $400{ }^{\circ} \mathrm{C}$, the $v(\mathrm{C}=\mathrm{C})$ and $\delta(\mathrm{CH})$ peaks were even more decreased and became unobvious when the temperature surpassed $600{ }^{\circ} \mathrm{C}$. This result indicated that the aliphatic $\mathrm{C}-\mathrm{H}$ was converted to $\mathrm{CO}_{2}, \mathrm{CH}_{4}$ and other gases or transformed into aromatic structures with pyrolysis temperature higher than $400{ }^{\circ} \mathrm{C}$ ( $\mathrm{Lu}$ et al. 2013). The tiny peaks of $v_{\mathrm{as}}\left(-\mathrm{CH}_{2}\right)$ and $v_{\mathrm{s}}\left(-\mathrm{CH}_{2}\right)$ compared with the much more significant $v(\mathrm{C}-\mathrm{O})$ implied that PM and $\mathrm{CM}$ were dehydrogenated accompanied by the formation of C-O-C groups as different forms of oxygen were converted into carbon chains with carbon-oxygen form (Ho et al. 2017). The high temperature eliminated most functional groups and transformed part of them into carbonaceous structures, which led to the graphitization of biochar. This conclusion is supported by the ultimate analysis in Table 1, where the higher temperature decreased the content of $\mathrm{H}$ and $\mathrm{O}$ while stabilized the content of C. 


\subsection{Effect of pyrolysis temperature on heavy metals immobilization}

\subsubsection{Total concentrations of heavy metals in PM, CM and their biochars}

The heavy metals contents in PM, CM and their biochars were important factor for their treatment and application. Thus it was necessary to investigate the immobilization and migration of the heavy metals during pyrolysis process. The total concentrations of heavy metals in PM, CM and their biochars were listed in Table 2. For all the heavy metals, only $\mathrm{Zn}$ and $\mathrm{Cu}$ presented relative high concentrations of $2739.58 \mathrm{mg} / \mathrm{kg}$ vs $2332.27 \mathrm{mg} / \mathrm{kg}$ and $610.22 \mathrm{mg} / \mathrm{kg}$ vs $741.32 \mathrm{mg} / \mathrm{kg}$ in PM and CM, respectively, and the concentration of $\mathrm{Zn}$ exceeded its threshold value of 2000.00 $\mathrm{mg} / \mathrm{kg}$. It was also reported by other research that the concentrations of $\mathrm{Zn}$ and $\mathrm{Cu}$ in PM were extremely higher than other kinds of heavy metals, which contributed by the high $\mathrm{Zn}$ and $\mathrm{Cu}$ concentrations in the food additives for livestock (Meng et al. 2017). In terms of all the heavy metals (except $\mathrm{Cd}$ ) in biochar samples, they concentrated during pyrolysis, and higher pyrolysis temperature led to higher concentration. It was interpreted by the decomposition of organic matters and lose of volatile matters in the PM and CM. The heavy metals were released during the decomposition process and then co-precipitated with the produced biochar (Wang et al. 2016). Another reason for the higher concentrations of heavy metals in biochar samples was that the lose weight of organic matters was higher than that of heavy metals (Wang et al. 2016). While, the concentration of $\mathrm{Cd}$ rose first and then dropped with the increase of pyrolysis temperature. The main reason was that the $\mathrm{Cd}$ mainly existed as the form of carbonate and volatilized at higher pyrolysis temperature (Wang et al. 2019b). For PM, although the heavy metals concentrated in the biochar samples, it still did not exceed the threshold values except $\mathrm{Zn}$. While for $\mathrm{CM}$, the concentration of $\mathrm{Cu}$ exceeded the threshold value of $1500.00 \mathrm{mg} / \mathrm{kg}$ when the pyrolysis temperature was higher than 
$600{ }^{\circ} \mathrm{C}$ with $1545.19 \mathrm{mg} / \mathrm{kg}$. Therefore, the $\mathrm{Zn}$ and $\mathrm{Cu}$ were the mainly influential heavy metals in livestock and their biochars.

\subsubsection{Speciation distributions of heavy metals in PM, CM and their biochars}

In fact, the bioavailability and toxicity of heavy metals on the environment were mainly related to their chemical speciation. The chemical speciation assessed by BCR sequential extraction scheme could be divided into four fractions, which lowered in bioavailability and mobilization by F1 $>$ F2 $>$ F3 $>$ F4. The speciation distributions of different heavy metals in PM, CM and their biochar samples were presented in Fig. 2.

$\mathrm{Zn}$ and $\mathrm{Cu}$ were the essential trace elements for livestock and poultry, and their salt compounds were widely applied as food additives for livestock (Lin et al. 2017; Tiquia. 2010). The excess additives cannot be adsorbed efficiently by livestock, resulting in the high concentrations in PM and CM (Table 2). The Zn showed high bioavailability with F1 + F2 fractions of $58.09 \%$ in $\mathrm{PM}$ and $27.60 \%$ in $\mathrm{CM}$, respectively. With the pyrolysis temperature increasing from 300 to $700{ }^{\circ} \mathrm{C}$, the proportion of $\mathrm{F} 1+\mathrm{F} 2$ fractions declined in their biochar samples $(26.75 \%$ and $17.10 \%$ in biochar samples at $700{ }^{\circ} \mathrm{C}$ ). Even the fraction of $\mathrm{Zn}$ transformed from F1 + F2 fractions to F3 + F4 fractions, its percentage was still high in the biochar samples. Different from $\mathrm{Zn}$, the F3 fraction accounted for the main proportion of $\mathrm{Cu}$ in the $\mathrm{PM}$ and $\mathrm{CM}$ with $96.35 \%$ and $68.74 \%$, respectively. As the concentration of $\mathrm{Cu}$ in its biochar exceeded the threshold value, its chemical speciation should be paid much attention. With the increase in pyrolysis temperature, the F3 fraction converted remarkably into F4 fraction. And the F3 + F4 fractions reached to $99.09 \%$ and $99.44 \%$ in the biochar samples obtained at $700{ }^{\circ} \mathrm{C}$, indicating its slight risk on environment. The change was explained by the $\mathrm{Cu}$-organic matter complexes owned high stability, and it was also reported that $\mathrm{Cu}$ was mainly existed in organic and 
residual phase (Shi et al. 2013). As for Cr, F3 + F4 (mainly F4) occupied large part of the fractions in the PM and CM with $98.19 \%$ and $89.77 \%$, then changed to $99.95 \%$ and $99.60 \%$ at $700{ }^{\circ} \mathrm{C}$, respectively. And the $\mathrm{F} 4$ fraction of $\mathrm{Pb}$ (only for $\mathrm{CM}$ ) almost occupied $100 \%$ in the biochar obtained even at low pyrolysis temperature of $300{ }^{\circ} \mathrm{C}$.

In terms of $\mathrm{Ni}, \mathrm{Cd}$ and $\mathrm{As}$, similar with $\mathrm{Cr}$ and $\mathrm{Pb}$, their concentrations in their raw manures and biochar samples did not surpass their threshold values of 100.00 $\mathrm{mg} / \mathrm{kg}, 5.00 \mathrm{mg} / \mathrm{kg}$ and $300.00 \mathrm{mg} / \mathrm{kg}$ at $\mathrm{pH}<6.5$ (Table 2). While, their bioavailable fractions (F1 + F2) were relevant higher than those of $\mathrm{Cr}$ and $\mathrm{Pb}$, so their immobilization performance should be focused on. The F1 + F2 fractions of Ni were $28.55 \%$ and $22.06 \%$ in $\mathrm{PM}$ and $\mathrm{CM}$, and then reduced to $0.89 \%$ and $4.00 \%$ in the biochar samples at $300{ }^{\circ} \mathrm{C}$ respectively, moreover higher pyrolysis temperature had little influence in the proportion. Another obvious change was the decline of F3 fraction and increase of $\mathrm{F} 4$ fraction with rising temperature from 300 to $700{ }^{\circ} \mathrm{C}$. The $\mathrm{Cd}$ and As presented the same trend with $\mathrm{Ni}$, indicating their well transformation from unstable fractions of $\mathrm{F} 1+\mathrm{F} 2$ to stable fractions of $\mathrm{F} 3+\mathrm{F} 4$.

According to the above results, the F1, F2, F3 and F4 fractions had different distribution for different heavy metals in the PM, CM and their biochar samples. While, the stable fractions of F3 + F4 obviously increased after pyrolysis and higher pyrolysis temperature led to higher percentage.

\subsubsection{Leaching characterization and ecological risk assessment}

The TCLP method was used to assess the leaching characterization of different heavy metals in PM, CM and their biochars, and the results were listed in Table S3 and Fig. 3. As for raw PM, the leaching concentration of $\mathrm{Zn}$ was relevant high with $25.95 \mathrm{mg} / \mathrm{L}$, which exceeded its threshold value of $5.00 \mathrm{mg} / \mathrm{L}$, indicating its high potential environmental risk. The other heavy metals including $\mathrm{Cr}, \mathrm{Ni}, \mathrm{Cd}, \mathrm{As}$ and $\mathrm{Pb}$ 
had low leaching concentrations. After pyrolysis, the leaching concentrations of all the heavy metals reduced and higher pyrolysis temperatures led to lower leaching concentrations. But the concentration of $\mathrm{Zn}$ in biochar obtained at $700{ }^{\circ} \mathrm{C}$ was 16.36 $\mathrm{mg} / \mathrm{L}$, being still higher than the threshold value of $5.00 \mathrm{mg} / \mathrm{L}$. The leaching rates of PM, CM and their biochar samples were presented in Fig. 3. The leaching rates of all the seven heavy metals obviously reduced with pyrolysis temperature. This also verified that the decline toxicity of the leached heavy metals in the biochar samples. Similar to the changes of PM, the pyrolysis technology also presented enhancement effect on the leaching concentrations and leaching rates for $\mathrm{CM}$. The difference was that all the leaching concentrations of the heavy metals in biochar from $\mathrm{CM}$ were lower than their threshold values, indicating their low environmental risk.

The risk assessment codes of different heavy metals in PM, CM and their biochars were also summarized in Table 3. The biochar samples performed safer state compared with the raw materials. For the PM, Zn presented high risk, and Ni and As were listed as moderate risk. Other heavy metals were low risk or no risk. After pyrolysis at $700{ }^{\circ} \mathrm{C}$, the risk states of $\mathrm{Zn}, \mathrm{Ni}$ and As transformed to moderate, no and low risk, respectively, which meant that the risk assessment of the heavy metals was extremely declined. Similar to the change of PM, the risk assessment of all the heavy metals in CM transformed to low risk/no risk after pyrolysis. It was also verified from the pyrolysis of sewage sludge that the heavy meals were well immobilized to decline the risk assessment during pyrolysis process (Jin et al. 2016; Li et al. 2018a). In summary, the pyrolysis presented obvious advantage in heavy metals immobilization during the safe treatment of PM and CM.

\subsection{Antibiotics removal during pyrolysis process}

\subsubsection{Total concentrations of different antibiotics in PM, CM and their biochars}


As there were many kinds of antibiotics in livestock feces, so three main classes

341 (macrolides, tetracyclines, sulfonamides) including seven typical antibiotics (TYL,

342

TC, CTC, DOXY, SMZ, SDZ and SMX) were selected to investigate the effect of pyrolysis temperature on the decomposition performance of the antibiotics. The concentrations of the seven antibiotics in the PM, CM and their biochars were presented in Table S4.

Among the seven antibiotics, the concentrations of TC, CTC and DOXY (905.13, 39890.50 and $95500.24 \mu \mathrm{g} / \mathrm{kg}$ in PM $v_{s} 3181.13,46100.34$ and $204.95 \mu \mathrm{g} / \mathrm{kg}$ in $\mathrm{CM}$ ) were extremely higher than those of other antibiotics. Because the TC is the universal antibiotics to enhance the growth of livestock, and the CTC and DOXY are used to prevent livestock from diseases. They were excessively used as additives during feeding livestock. The concentrations of other four antibiotics were relevant low. While, the concentrations of TYL, TC, CTC, DOXY and SDZ remarkably reduced after pyrolysis, and higher pyrolysis temperature resulted in lower concentrations. For TYL, TC, CTC and SMZ, their concentrations decreased to 0 $\mu \mathrm{g} / \mathrm{kg}$ (no detected) in the $\mathrm{PM}$ and $\mathrm{CM}$ biochar samples obtained at $300{ }^{\circ} \mathrm{C}$, indicating their easy decomposition properties. These performances could also be verified from their thermo-gravimetric analysis results (Fig. S2) that all the TYL, TC, CTC and SMZ presented a big weight loss peak near $300^{\circ} \mathrm{C}$. These meant that their structures were obviously changed due to the removal of part functional groups or break of some bonds converting into gases, which led to the loss of weight. In terms of DOXY, SDZ and SMX, their concentrations reduced with pyrolysis temperature increasing to $500{ }^{\circ} \mathrm{C}(<\mathrm{IQL})$. But they still needed much higher temperature of $600{ }^{\circ} \mathrm{C}$ for the thorough decomposition, indicating their difficult decomposition during pyrolysis process. And it can also be seen from Table S5 that the temperature ranges of weight 
loss of these antibiotics were relevant higher. This might explain their higher temperature requirement for completely decomposition. All in all, the pyrolysis technology presented many advantages than other treatment method like composting about antibiotics thorough removal (Pruden et al. 2013). The results indicated that $600{ }^{\circ} \mathrm{C}$ was the lowest pyrolysis temperature for completely removing all these antibiotics.

\subsection{Pilot-scale verification at optimal pyrolysis condition}

After the laboratory investigation, the pyrolysis temperature of $600{ }^{\circ} \mathrm{C}$ was selected for pilot-scale verification in a rotary furnace (Li et al. 2018a), confirming the performances of heavy metals immobilization and antibiotics removal in the PM and CM. The pyrolysis temperature was practically controlled at $600 \pm 50{ }^{\circ} \mathrm{C}$, and the biochar yields of $\mathrm{PM}$ and $\mathrm{CM}$ were $35.60 \%$ and $36.84 \%$, respectively. The concentrations of heavy metals and antibiotics, heavy metals immobilization and antibiotics removal rate in the biochar were investigated.

Heavy metals immobilization : The total concentrations, risk assessment code

and leaching concentrations of all the heavy metals in the biochar samples from pilotscale tests were also measured (Table 2, Table 3 and Table S3). It can be seen that similar data were obtained from pilot-scale tests compared with those from laboratory-scale experiments at the same pyrolysis condition. A little higher concentrations of all the heavy metals in pilot-scale biochar were caused by the difficulty at controlling exact temperature at $600{ }^{\circ} \mathrm{C}$, sometime the pyrolysis temperature was higher than $600{ }^{\circ} \mathrm{C}$. Meantime, the pilot-scale test using rotary furnace with better heat transfer than laboratory-scale test using fixed bed reactor. The risk assessment codes of the heavy metals in the pilot biochars were also reduced after pyrolysis at $600{ }^{\circ} \mathrm{C}$. And the leaching concentration for all the heavy metals showed 
that only $\mathrm{Zn}$ exceeded its permissible limit in pilot PM biochar. All the other heavy metals in PM and CM biochars did not pass their threshold values, indicating their low environmental risk.

The speciation distributions of different heavy metals in the pilot biochars were presented in Fig. 4a. Obvious immobilization was completely obtained with conversion from the unstable F1 + F2 fractions to the stable F3 + F4 fractions.

Antibiotics removal: In terms of antibiotics removal performance in the pilot-scale test, the concentrations of seven typical antibiotics in the biochar were measured (Table S4). And their removal rates were presented in Fig. 4b. Similar to the results from laboratory-scale tests, there were no antibiotics detected in the pilot-scale biochar, and all their removal rates reached to $100 \%$. These results also verified that the antibiotics were entirely decomposed during pyrolysis at $600{ }^{\circ} \mathrm{C}$ in the pilot-scale tests.

In summary, better performances in the heavy metals immobilization and the antibiotics removal were obtained in the pilot-scale tests. Through the pilot-scale verification, it was proved that the pyrolysis technology presented much advantages in safe treatment and recycle of livestock manures via production of biochar.

\section{Conclusions}

In this study, PM and CM were converted into biochar through pyrolysis at different temperatures from 300 to $700{ }^{\circ} \mathrm{C}$, focusing on the performance investigations of the heavy metals immobilization and antibiotics removal. The following conclusions were obtained:

(1) The heavy metals in PM and CM were significantly immobilized with converting bio-available fractions to more stable-biological ineffectiveness fractions and the higher pyrolysis temperatures (above $600{ }^{\circ} \mathrm{C}$ ) favored the heavy metal 
(2) The typical antibiotics contained in the PM and CM were greatly removed

by pyrolysis process, and they can be completely removed with pyrolysis temperature increasing to $600{ }^{\circ} \mathrm{C}$.

(3) The optimal temperature of $600{ }^{\circ} \mathrm{C}$ was selected for pilot-scale verification in a rotary furnace and the similar good results in antibiotics removal and heavy metals immobilization were obtained.

(4) The pyrolysis provided an effective method to immobilize and remove the harmful matters including heavy metals and antibiotics for safe treatment and application of PM and CM.

\section{Acknowledgments}

All the authors are grateful for the support provided by the Strategic Priority Research Program of the Chinese Academy of Sciences (Grant No. XDA23030301), the China-Japanese Research Cooperative Program-China (No. 2016YFE0118000) and the Scientific and Technology Major Special Project of Tianjin City (16YFXTSF00420).

\section{References}

Agrafioti E, Bouras G, Kalderis D, Diamadopoulos E (2013) Biochar production by sewage sludge pyrolysis. J Anal Appl Pyrol 101:72-78

Ehsan M, Barakat MA, Husein DZ, Ismail SM (2014) Immobilization of Ni and Cd in Soil by Biochar Derived From Unfertilized Dates. Water Air Soil Poll 225(11):2123

Feng Z, Zhu H, Deng Q, He Y, Li J, Yin J, Gao F, Huang R, Li T (2018) Environmental pollution induced by heavy metal(loid)s from pig farming. Environ Earth Sci 77(3):103

Harvey OR, Herbert BE, Rhue RD, Kuo LJ (2011) Metal interactions at the biochar-water interface: energetics and structure-sorption relationships elucidated by flow adsorption microcalorimetry. Environ Sci Technol 45:5550-5556

Ho SH, c, Yang ZK, Nagarajan D, Chang JS , Ren NQ (2017) High-efficiency removal of lead from wastewater by biochar derived from anaerobic digestion sludge. Bioresour Technol 246:142149

Huang Y, Cheng M, Li W, Wu L, Chen Y, Luo Y, Christie P, Zhang H (2013) Simultaneous extraction of four classes of antibiotics in soil, manure and sewage sludge and analysis by liquid chromatography-tandem mass spectrometry with the isotope-labelled internal standard method. Anal Methods 5:3721

Jin J, Li Y, Zhang J, Wu S, Cao Y, Liang P, Zhang J, Wong MH, Wang M, Shan S, Christie P (2016) 
Influence of pyrolysis temperature on properties and environmental safety of heavy metals in biochars derived from municipal sewage sludge. J Hazard Mater 320:417-426

Khorram MS, Zhang Q, Lin D, Zheng Y, Fang H, Yu Y (2016) Biochar: A review of its impact on pesticide behavior in soil environments and its potential applications. J Environ Sci 44:269279

Leng L, Yuan X, Shao J, Huang H, Wang H, Li H, Chen X, Zeng G (2016)Study on demetalization of sewage sludge by sequential extraction before liquefaction for the production of cleaner biooil and bio-char. Bioresour Technol 200:320-327

Li C, Wang X, Zhang G, Li J, Li Z, Yu G, Wang Y (2018a) A process combining hydrothermal pretreatment, anaerobic digestion and pyrolysis for sewage sludge dewatering and coproduction of biogas and biochar: Pilot-scale verification. Bioresour Technol 254:187-193

Li J, Yu G, Pan L, Li C, You F, Xie S, Wang Y, Ma J, Shang X (2018b) Study of ciprofloxacin removal by biochar obtained from used tea leaves. J Environ Sci 73:20-30

Lin Q, Xu X, Wang L, Chen Q, Fang J, Shen X, Lou L, Tian G (2017) The speciation, leachability and bioaccessibility of $\mathrm{Cu}$ and $\mathrm{Zn}$ in animal manure-derived biochar: effect of feedstock and pyrolysis temperature. Front Env Sci Eng 11:68-78

Lu H, Zhang W, Wang S, Zhuang L, Yang Y, Qiu R (2013) Characterization of sewage sludge-derived biochars from different feedstocks and pyrolysis temperatures. J Anal Appl Pyrol 102:137-143

Meng J, Wang L, Zhong L, Liu X, Brookes PC, Xu J, Chen H (2017) Contrasting effects of composting and pyrolysis on bioavailability and speciation of $\mathrm{Cu}$ and $\mathrm{Zn}$ in pig manure. Chemosphere 180:93-99

Pruden A, Larsson DG, Amezquita A, Collignon P, Brandt KK, Graham DW, Lazorchak JM, Suzuki S, Silley P, Snape JR, Topp E, Zhang T, Zhu YG (2013) Management options for reducing the release of antibiotics and antibiotic resistance genes to the environment. Environ Health Persp 121:878-885

Qian L, Chen L, Joseph S, Pan G, Li L, Zheng J, Zhang X, Zheng J, Yu X, Wang J (2014) Biochar compound fertilizer as an option to reach high productivity but low carbon intensity in rice agriculture of China. Carbon Manag 5(2):145-154

Qiao M, Chen W, Su JQ, Zhang B, Zhang C (2012) Fate of tetracyclines in swine manure of three selected swine farms in China. J Environ Sci 24:1047-1052

Shi W, Liu C, Ding D, Lei Z, Yang Y, Feng C, Zhang Z (2013) Immobilization of heavy metals in sewage sludge by using subcritical water technology. Bioresour Technol 137:18-24

Tan Z, Lin CSK, Ji X, Rainey TJ (2017) Returning biochar to fields: A review. Appl Soil Ecol 116:1-11

Tiquia SM (2010) Reduction of compost phytotoxicity during the process of decomposition. Chemosphere 79:506-512

Troy SM, Nolan T, Leahy JJ, Lawlor PG, Healy MG, Kwapinski W (2013) Effect of sawdust addition and composting of feedstock on renewable energy and biochar production from pyrolysis of anaerobically digested pig manure. Biomass Bioenerg 49:1-9

Uchimiya M, Bannon DI (2013) Solubility of lead and copper in biochar-amended small arms range soils: influence of soil organic carbon and pH. J Agr Food Chem 61:7679-7688

Wang H, Dong Y, Yang Y, Toor GS, Zhang X (2013) Changes in heavy metal contents in animal feeds and manures in an intensive animal production region of China. J Environ Sci 25:2435-2442

Wang X, Li C, Li Z, Yu G, Wang Y (2019b) Effect of pyrolysis temperature on characteristics, chemical speciation and risk evaluation of heavy metals in biochar derived from textile dyeing sludge. Ecotox Environ Safe 168:45-52

Wang X, Li C, Zhang B, Lin J, Chi Q, Wang Y (2016) Migration and risk assessment of heavy metals in sewage sludge during hydrothermal treatment combined with pyrolysis. Bioresour Technol 221:560-567

Wang X, Chi Q, Liu J, Wang Y (2019a) Influence of pyrolysis tem-perature on characteristics and environmental risk of heavy metals inpyrolyzed biochar made from hydrothermally treated sewage sludge. Chemosphere 216:698-706

Xie S, Yu G, Li C, You F, Li J, Tian R, Wang G, Wang Y (2019) Dewaterability enhancement and heavy metals immobilization by pig manure biochar addition during hydrothermal treatment of sewage sludge. Environ Sci Pollut Res https://doi.org/10.1007/s11356-019-04961-1

Yang H, Yan R, Chen H, Lee DH, Zheng C (2007) Characteristics of hemicellulose, cellulose and lignin pyrolysis. Fuel 86:1781-1788

Yang X, Li Q, Tang Z, Zhang W, Yu G, Shen Q, Zhao FJ (2017) Heavy metal concentrations and arsenic speciation in animal manure composts in China. Waste Manage 64:333

Yargicoglu EN, Sadasivam BY, Reddy KR, Spokas K (2015) Physical and chemical characterization of waste wood derived biochars. Waste Manage 36:256-268 
You F-T, Yu G-W, Xing Z-J, Li J, Xie S-Y, Li C-X, Wang G, Ren H-Y, Wang Y (2019) Enhancement of NO catalytic oxidation on activated carbon at room temperature by nitric acid hydrothermal treatment. Appl Surf Sci 471:633-644

Zeng X, Xiao Z, Zhang G, Wang A, Li Z, Liu Y, Wang H, Zeng Q, Liang Y, Zou D (2018) Speciation and bioavailability of heavy metals in pyrolytic biochar of swine and goat manures. J Anal Appl Pyrol 132:82-93

Zhai Y, Chen H, Xu B, Xiang B, Chen Z, Li C, Zeng G (2014) Influence of sewage sludge-based activated carbon and temperature on the liquefaction of sewage sludge: Yield and composition of bio-oil, immobilization and risk assessment of heavy metals. Bioresour Technol 159:72-79

Zhang Y, Chen T, Liao Y, Reid BJ, Chi H, Hou Y, Cai C (2016) Modest amendment of sewage sludge biochar to reduce the accumulation of cadmium into rice(Oryza sativa L.): A field study. Environ Pollut 216:819-825

Zheng H, Wang Z, Deng X, Zhao J, Luo Y, Novak J, Herbert S, Xing B (2013) Characteristics and nutrient values of biochars produced from giant reed at different temperatures. Bioresour Technol 130:463-471

Zheng J, Han J, Liu Z, Xia W, Zhang X, Li L, Liu X, Bian R, Cheng K, Zheng J, Pan G (2017) Biochar compound fertilizer increases nitrogen productivity and economic benefits but decreases carbon emission of maize production. Agr Ecosyst Environ 241:70-78

Zhou X, Qiao M, Su JQ, Wang Y, Cao ZH, Cheng WD, Zhu YG (2019b) Turning pig manure into biochar can effectively mitigate antibiotic resistance genes as organic fertilizer. Sci Total Environ 649:902-908

Zhou X, Qiao M, Su JQ, Zhu YG (2019a) High-throughput characterization of antibiotic resistome in soil amended with commercial organic fertilizers. J Soils Sediment 19:641-651 